2009-02-17

\title{
Profits, supply and HYV adoption in Bangladesh
}

\author{
Rahman, Sanzidur
}

http://hdl.handle.net/10026.1/4024

$10.1080 / 13547860802661538$

Journal of the Asia Pacific Economy

Informa UK Limited

All content in PEARL is protected by copyright law. Author manuscripts are made available in accordance with publisher policies. Please cite only the published version using the details provided on the item record or document. In the absence of an open licence (e.g. Creative Commons), permissions for further reuse of content should be sought from the publisher or author. 


\title{
Profits, supply and HYV adoption in Bangladesh
}

\author{
Sanzidur Rahman \\ School of Geography \\ University of Plymouth, Plymouth, PL4 8AA, UK
}

and

\section{Bhavani Shankar \\ Department of Agricultural and Food Economics, School of Agriculture University of Reading, Reading, RG6 6AR, UK}

\section{$\underline{\text { Address for Correspondence }}$}

Dr. Sanzidur Rahman

Senior Lecturer in Rural Development

School of Geography

Faculty of Social Science and Business

The University of Plymouth

Drake Circus

Plymouth, PL4 8AA, UK

Phone: +44-1752 585911

Fax: $\quad+44-1752585998$

E-mail: srahman@plymouth.ac.uk 


\title{
Profits, supply and HYV adoption in Bangladesh
}

\begin{abstract}
The adoption of HYV's, increased farm profitability, and the accelerated supply of cereals are important objectives for Bangladesh agriculture. In this paper, we have investigated the manner in which price and non-price factor affect these three criteria, based upon a model of rational variety choice. The model is empirically implemented using translog profit functions and a switching regression framework, and applied to a cross-sectional farm-level dataset of Bangladeshi farms for the 1996 crop year. Results indicate that rice prices, land availability, irrigation, rural infrastructure, labour wages and prices of animal power services are important factors, while fertilizer price play a marginal role. Given these results, the policy of liberalization of agricultural inputs (particularly fertilizers) and reforms to maintain high rice prices during harvest seasons appear sound since these allow producers to receive rice prices close to world levels without burdening the government with input subsidies. Result also shows that educated Bangladeshi farmers substitute their time inputs away from agriculture, resulting in lower HYV adoption, farm profitability and rice supply.
\end{abstract}

Key Words: HYV adoption, resource allocation decisions, profitability, Bangladesh.

JEL classification: Q12, O33, C31.

\section{Introduction}

Food security continues to be the predominant economic concern in Bangladesh even four decades after the advent of the 'Green Revolution'. Food production levels have registered continuing deficits, and the country does not possess the resources to make up chronic shortfalls through imports (Ahmed and Hasanuzzaman, 1998). The focus of concern has naturally been on rice which remains the staple sources of nutrition in Bangladesh. High Yielding Varieties (HYVs) of rice provide substantially better yields than the Traditional 
Varieties (TVs). Thus the push towards food security could be envisaged in terms of progress in two directions: first, an expansion in the area under HYVs and second, an increase in foodgrain supply at the farm-level. However, in spite of recent progress, Bangladesh has one of the lowest HYV adoption rates in Asia (Azam, 1998). Currently, only 61\% of rice area is under HYV rice (BBS, 2001). Additionally, there has been little improvement in farm-level variety specific rice yield (Mahmud, 1998). For example, farm-level yield of HYV and TV rice is estimated at $4.44 \mathrm{mt} / \mathrm{ha}$ and $2.81 \mathrm{mt} / \mathrm{ha}$ in 1987 (Hossain, et al., 1990). After nine years, in 1996, estimates of farm-level yield of HYV rice remained at $4.35 \mathrm{mt} / \mathrm{ha}$ while yield of TV rice increased slightly to $3.16 \mathrm{mt} / \mathrm{ha}$, largely owing to increased use of inorganic fertilizers in traditional varieties (Table 1). Furthermore, in a situation characterized by endemic rural poverty, farm profitability is an important concern. Economic returns are often very low in Bangladeshi farms. Even farming operations at the higher end of the profit scale may not be able to provide an adequate standard of living to the household (Hossain, 1989). In 1987, farm-level profits from HYV rice cultivation was $123.5 \%$ higher than the traditional varieties (Hossain et al., 1990) which now have declined to only 41.9\% in 1996 (Table 1).

Given these continuing problems even with the 'Green Revolution' now in its mature stage, important lessons can be learned from an exercise that jointly evaluates the determinants of (i) HYV adoption, (ii) variety-specific supply and (iii) profitability at the level of the individual producer. We undertake such a task in this paper by applying a model of technology adoption developed by Pitt (1983) to an extensive cross-sectional production dataset for 1996. The nature of the empirical model, in combination with the level of detail in the dataset, enables us to evaluate key price and non-price determinants on all three fronts mentioned above. In light of the evidence, we comment on how consistent recently implemented policies might be with the three criteria, and suggest directions for the future. 
The next section reviews relevant prior research concerning determinants of HYV and/or modern technology adoption in Bangladesh and elsewhere. Section 3 explains the theoretical and empirical underpinnings of our model. Sections 4 and 5 lay out our empirical specification and details regarding the data, respectively. Results are presented and discussed in Section 6. Section 7 investigates implication with respect to policy in Bangladesh and concludes.

\section{Studies analyzing determinants of technology adoption}

Several studies have analyzed determinants of adoption of modern/improved technologies (including HYVs of rice, wheat and/or maize) by farmers in Bangladesh and elsewhere using simple ad-hoc models. These are typically OLS, probit or tobit regressions of technology adoption on variables representing: (a) socio-economic circumstances of farmers - such as, farm size, tenurial status, farmer education levels, farming experience, family size, and gender, and (b) institutional and physical infrastructures - such as, irrigation, credit, extension contacts, membership in organizations, and distance to markets/bus stops/extension offices (e.g., Kashem, 1987; Hossain, 1989; Ahmed and Hossain, 1990; Alauddin and Tisdel, 1991; Nkamleu and Adesina, 2000; Shiyani, et al., 2002; Floyd et al., 2003; Ransom, et al., 2003; Asfaw and Admassie, 2004). Few of these studies outlined implicit theoretical underpinning of such ad-hoc modelling (e.g., Nkamleu and Adesina, 2000) which is the assumption of utility maximization by rational farmers. Furthermore, all of these studies ignored or omitted price factors (both input and output prices) as determinants of technology adoption which has important bearing on profitability and resource allocation decisions, and concentrated only on non-price factors discussed above, hence providing an incomplete picture of farmer's decision-making process.

Among the non-price determinants, that irrigation and credit availability are critical to HYV adoption are results that this literature on Bangladesh has reached a consensus on. 
Among the more interesting and controversial factors is the education of the farmer. While Kashem (1987) finds that education encourages HYV adoption, Hossain (1989) comes to the opposite conclusion in case of Bangladeshi farmers. Elsewhere, the results are similarly controversial. For example, Nkamleu, and Adesina (2000) and Asfaw and Admassie (2004) concluded that education is important in influencing adoption of chemical inputs in Cameroon and Ethiopia; whereas Ransom et al., (2004) and Shiyani et al., (2002) found no significant influence of education on the adoption of improved maize in Nepal and chickpea in India, respectively.

There is a difference in the survival probabilities of HYV and TV rice crops under flood conditions. This factor is likely to influence adoption rates and be instrumental in determining the time path of diffusion of HYV technology, especially in a flood-prone country like Bangladesh. Such reasoning forms the basis underlying a small but interesting literature, including Bera and Kelly (1990) and Azam (1996). Both studies concluded that adoption of HYV technology is influenced by flood damage, among other factors. Another important contribution is that of Parikh and Bernard (1988), who infers the attitudes of rice farmers to risk by their adoption or non-adoption of riskier modern varieties. They concluded that large holders of land tended to be relatively more risk-averse than small holders of land and level of HYV adoption declines with increase in land size. Shiyani, et al., (2002) concluded that yield risk significantly influence improved chickpea adoption in India with the expectation that adoption of improved variety will minimize yield variability.

The contribution of this study to the literature on the economics of HYV adoption can be understood by considering the following points:

(1) As pointed out previously, several of the empirical studies on adoption were ad-hoc and not specified on the basis of models of farmer behaviour. Models based on explicit 
optimizing behaviour can provide a better understanding of the process by which external factors determine adoption ${ }^{1}$.

(2) The majority of previous studies have used cross-sectional data pertaining to the early and middle stages of HYV adoption. Besley and Case (1993) point out that where the technology is incompletely diffused through the population, parameters estimated from single cross-sections can be hard to interpret. They also note that once the diffusion process is complete, cross-sectional studies can provide insights into how farm characteristics affect adoption.

More than thirty-five years have passed since improved varieties were first introduced in Bangladesh. Knowledge regarding HYV techniques has spread widely among the producers, and it is easier now to view adoption as an informed choice made by rational producers. Thus not only our data are more representative of the existing state of affairs, but the model we employ is more reflective of the current climate of informed decision-making and explicitly takes into account both price and non-price factors influencing adoption.

\section{The Model ${ }^{2}$ :}

Farmers are viewed as profit-maximizing agents who make two sets of decisions. One is a choice between TV and HYV technologies and the second the choice of variable inputs, given the chosen technology. The set of output and input prices and the set of fixed factors thus determine all variables of interest: the choice between varieties, variety-specific output supply, input demands and profits ${ }^{3}$.

\footnotetext{
${ }^{1}$ This is akin to the relative advantages of estimating structural form vs. reduced form equations. It is always possible to go from the structural form to the reduced form, but not vice-versa.

${ }^{2}$ This section is based on Mark Pitt's model of technology adoption. We only provide a synopsis of the model here. Readers interested in further details are referred to Pitt (1983).

${ }^{3}$ By characterizing farmers as profit maximizers, we are ignoring considerations of risk. Parikh and Bernard (1988) tackle the issue of risk and HYV adoption in Bangladesh.
} 
The model can be described by a system of simultaneous equations specifying profits under traditional and HYV technologies and a criterion function representing the selection process:

$$
\begin{aligned}
& \pi_{h i}=P_{i} \beta_{h}+Z_{i} \gamma_{h}+\varepsilon_{h i} \\
& \pi_{l i}=P_{i} \beta_{l}+Z_{i} \gamma_{l}+\varepsilon_{l i} \\
& I^{\prime}=\left(\pi_{h i}-\pi_{l i}\right) \lambda-\varepsilon_{i} \\
& \varepsilon_{h} \approx N\left(0, \sigma_{h}^{2}\right), \varepsilon_{l} \approx N\left(0, \sigma_{l}^{2}\right), \varepsilon_{i} \approx N\left(0, \sigma_{\varepsilon}^{2}\right)
\end{aligned}
$$

where: $\pi_{h i}$ profits under HYV variety, $\pi_{l i}$ profits under traditional variety, $P_{i}$ vector of output and variable input prices, $Z_{i}$ vector of fixed inputs, $\beta_{h}, \beta_{l}, \gamma_{h}, \gamma_{l}$, and $\lambda$ are vectors of parameters, I' unobserved (latent) variable determining choice of varieties, $\varepsilon_{h}, \varepsilon_{l}, \varepsilon_{i}$, are random errors and $\mathrm{i}$ indexes individuals.

The model sets out the variety selection procedure (3) as a process (subject to error) that weighs alternative profits under the traditional and HYV regimes \{represented by the profit functions in (1) and (2)\}. Of course, only the ex-post decision is observed, which can be represented by a dummy variable $I$. Therefore:

$$
\begin{aligned}
I_{i} & =1, \text { if } I_{i}^{\prime} \geq 0 \\
& =0, \text { otherwise }
\end{aligned}
$$

In this model of rational variety choice, estimation of either (1) or (2) using observations from a single variety alone is likely to produce biased estimates. This happens because the omission of a particular variety from estimation leads to non-zero conditional expectation of the error terms of individual profit functions. However, with a sample consisting of observations from both varieties, the following two-step estimation strategy can provide unbiased estimates of variety specific profit functions (Heckman, 1976; Lee, 1976 and Pitt, 1983).

(i) Substituting the variety-specific profit functions (1) and (2) into the latent variety-selection equation (3) provides a reduced-from linear variety-selection equation given by: 
$I^{\prime}=\eta_{0}+\mathrm{P}_{i} \Omega_{1}+\mathrm{P}_{i} \Omega_{2}+\varepsilon^{*}$

Replacing the latent variable with the observed adoption dummy enables (5) to be estimated by probit methods.

(ii) The estimate of (5) can be used in computing 'correction terms' that enables the conditional expectation of error terms of individual profit functions (1) and (2) to be zero. Consequently, variety-specific profit functions estimated with the appropriate correction term included among the regressors are consistent and unbiased (Heckman, 1976; Lee, 1976; Pitt, 1983).

The following features can be noted regarding the model:

(i) Probit estimation of (5) not only enables the estimation of a correction factor to remove bias in variety-specific profit function estimates, but also provides information on how price and non-price variables affect the probability of adoption.

(ii) The empirical probit equation is derived from the optimizing behaviour. The adoption decision is seen as a purely economic outcome where a variable can affect the probability of adoption only if it belongs in the profit function.

(iii)Second-stage variety-specific profit function estimates provide added information on how the key price and non-price factors affect farm profitability and output supplies.

Our three criteria can thus be evaluated in mutually consistent fashion.

\section{Empirical specification}

Translog functions are used to represent the variable profit functions of traditional and HYVs of rice, equations (1) and (2). The normalized restricted translog profit function can be written as:

$$
\begin{gathered}
\ln \pi^{\prime}=\alpha_{0}+\alpha_{i} \sum_{i=1}^{n} \ln P_{i}^{\prime}+1 / 2 \sum_{i=1}^{n} \sum_{h=1}^{n} \gamma_{i h} \ln P_{i}^{\prime} \ln P_{h}^{\prime}+\sum_{i=1}^{n} \sum_{k=1}^{m} \delta_{i k} \ln P_{i}^{\prime} \ln Z_{k}+\sum_{k=1}^{m} \beta_{k} \ln Z_{k} \\
+1 / 2 \sum_{k=1}^{m} \sum_{j=1}^{m} \psi_{k j} \ln Z_{k} \ln Z_{j}
\end{gathered}
$$


where $\pi^{\prime}$ is the restricted profit (total revenue less total costs of variable inputs) normalized by output price $P_{y}, P_{i}$ is the price of variable input $X_{i}$, normalized by the output price, $Z_{k}$ is the $k$ th fixed input; $i=h=1, \ldots . . n ; k=j=1, \ldots m . \alpha_{0}, \alpha_{i}, \gamma_{i h}, \beta_{k}, \delta_{i k}$, and $\psi_{k j}$, are parameters to be estimated, given symmetry and homogeneity restrictions.

From the profit function (6), the following share equations can be derived (Diewert, 1974; Sidhu and Baanante, 1981):

$$
-S_{i}=-\frac{P_{i}^{\prime^{\prime}} X_{i}}{\pi^{\prime}}=\frac{\partial \ln \pi^{\prime}}{\partial \ln P_{i}^{\prime}}=\alpha_{i}+\sum_{h=1}^{n} \gamma_{i h} \ln P_{h}^{\prime}+\sum_{k=1}^{m} \delta_{i k} \ln Z_{k}
$$

where $S_{i}$ is the variable expenditure for the ith input divided by total profits.

Our estimation proceeds along the lines outlined in the previous section. To summarize:

(i) A probit estimate of the variety-selection equation (5) is obtained by using maximum Likelihood (ML) methods on cross-sectional data. Since profit functions are translog, the reduced form variety-selection equation (5) also has a translog form. The probit equation can thus be written as:

$$
\begin{gathered}
\widehat{\theta}=\mu_{0}+\mu_{1 i} \sum_{i=1}^{n} \ln P_{i}^{\prime}+1 / 2 \sum_{i=1}^{n} \sum_{h=1}^{n} \mu_{2 i h} \ln P_{i}^{\prime} \ln P_{h}^{\prime}+\sum_{i=1}^{n} \sum_{k=1}^{m} \mu_{3 i k} \ln P_{i}^{\prime} \ln Z_{k}+\sum_{k=1}^{m} \mu_{4 k} \ln Z_{k} \\
+1 / 2 \sum_{k=1}^{m} \sum_{j=1}^{m} \mu_{5 k j} \ln Z_{k} \ln Z_{j}+\mu_{6} D
\end{gathered}
$$

where $\hat{\theta}$ is a dummy variable taking the value 1 if the plot is planted to HYV rice and 0 otherwise, $D$ is the dummy variable representing seasonality, $\mu$ 's are the parameters to be estimated. Rest of the variables is defined earlier.

(ii) Inverse Mill's Ratios (IMR) for each member of the cross-section are computed. The IMRs are given by $-f(\hat{\theta}) / F(\hat{\theta})$ for HYV observations, and $f(\hat{\theta}) /[1-F(\hat{\theta})]$ for observation using traditional varieties (Heckman, 1976; Davidson and McKinnon, 1993). (iii)Two different profit functions are estimated for HYV and TV, respectively. 
These profit function includes correction factors computed in (ii) as regressors and are hence consistent and unbiased. Since the estimation of share equations (7) along with profit functions are known to yield more efficient estimates (Heckman, 1976), we undertake such joint estimation using Seemingly Unrelated Regressions (SUR) procedure.

\section{Data and variables}

This study utilizes cross-sectional primary data for the crop year 1996. The data were collected by a team of field researchers via an intensive farm-survey coordinated by one of the authors of this paper. Multistage random sampling techniques were used in selecting study locations as well as the sample farmers. Three agro-ecological regions of Bangladesh are represented in the dataset: the Old Brahmaputra Floodplain, the High Ganges River Floodplain and the Middle Meghna River Floodplain. Samples from 21 villages - eight villages of the Jamalpur Sadar sub-district of Jamalpur, six villages of the Manirampur subdistrict of Jessore, and seven villages of the Matlab sub-district of Chandpur - were used to represent these regions.

Information was obtained on input and output quantities as well as prices, at the plot level. Additionally, socio-economic characteristics of the farm families and village-level infrastructural development data were also recorded. The geographical dispersion of the sample plots and imperfections in input markets in Bangladesh ensure adequate variability in prices across the cross-section ${ }^{4}$. In our sample, rice price varied from Tk 3.75 to Tk 7.5 per $\mathrm{kg}$; fertilizer price varied from Tk 4.00 to $\mathrm{Tk} 10.00$ per $\mathrm{kg}$; labour wage varied from $\mathrm{Tk}$. 25.00 to Tk 65.00 per person-day, and price of animal power services varied from Tk. 30 to

\footnotetext{
${ }^{4}$ Input and output prices vary in rural Bangladesh during period of peak demand. For example, price of fertilizers and labour wage soar dramatically during peak sowing seasons. Several factors beyond the control of the farmers are largely responsible for such variation in price, including hoarding by wholesalers, supply disruptions due to frequent transport strikes and other similar events, and relative shortage of hired labour during peak transplanting season.
} 
Tk. 110 per animal-pair days, respectively. A formal F-test for differences in the prices of fertilizers, labour wage, animal power services and the rice across 21 villages in each of the three cropping seasons (i.e., Aus, Aman and Boro season) under study rejected the nullhypothesis of "no-difference" at $1 \%$ level for all, thereby confirming that significant price variation exists in our sample, and hence, the application of the profit function model is justified. A total of 946 observations (324 observations of traditional rice varieties and 622 observations of HYV rice varieties) constitute the final sample. The variables used for this research are as follows:

Outputs: Quantities, varieties and prices of rice produced.

Variable inputs: Quantities and prices of fertilizers, labour and animal power services.

Fixed inputs: Quantities of land, value of farm capital assets, index of infrastructural underdevelopment ${ }^{5}$, and irrigation cost.

Other variables: Farmers' education and seasonality dummy.

Infrastructural development is a key limiting factor in the development of Bangladeshi agriculture (Ahmed and Hossain, 1990). Areas with better infrastructural development can realize higher productivity levels than infrastructurally underdeveloped areas for several reasons: extension information reaches them more easily and delivery of modern inputs such as fertilizers is timelier.

\footnotetext{
${ }^{5}$ The index of infrastructure was constructed using the 'cost of access' approach. A total of 13 elements were considered for its construction. These are, (1) primary market, (2) secondary market, (3) storage facility, (4) rice mill, (5) paved road, (6) bus stop, (7) bank, (8) union office, (9) agricultural extension office, (10) high school, (11) college, (12) thana (sub-district) headquarter, and (13) post office. The distance of these facilities from the village and the travel cost incurred to access these facilities was utilized to construct the index. High index value refers to high under developed infrastructure (for details of construction procedure, see Ahmed and Hossain, 1990).
} 
Summary statistics of all variables are presented in Table 1 . It is clear from Table 1 that HYV technology provides significantly higher yield as well as profits per hectare. Therefore, the premise that difference in profit between HYV and TV as a main determinant in variety selection is justified. Table 1 further confirms input intensive nature of the HYV technology as all three variable input quantities used are significantly higher in HYV rice production as compared to traditional rice varieties. Therefore, input and output prices is expected to play a key role in the decision making process. These results corroborate with studies by Hossain (1989), Ahmed and Hossain (1990), and Hossain et al., (1990).

\section{Results and discussions}

Prior to using the estimates to evaluate the effects of price and non-price factors on our three criteria, we discuss estimation diagnostics briefly.

Results from the (first stage) maximum likelihood estimation of the probit reduced form variety-selection equation in (8) are presented in Table 2 . It should be noted that the estimates in their 'raw' form do not provide information on the sign and magnitude of the relationship between the independent variables and the probability of HYV adoption. The Chi-squared test statistic is significant at the $1 \%$ level, confirming joint significance of parameters. About $81 \%$ of the observations are accurately predicted. A total of 16 parameters out of 45 are significant at the $10 \%$ level at least.

Second stage SUR estimates of the TV and HYV profit equations are presented in Table 3. The F-test statistic confirms that the set of parameters are jointly significant at $1 \%$ level for both profit functions. A large proportion of the set of parameters is significant at $1 \%$ and 5\% levels, respectively. The selectivity variable in the TV profit function is significant at $5 \%$ level, which confirms that estimation using observations from only a single variety will produce biased estimates due to the reason discussed in section 3 . 
Studies estimating profit functions typically present own and cross-price input demand elasticities. However, such an endeavour here would shift the focus of this research, and hence we do not present input demand information. We proceed by evaluating the effects of changes in input and output prices and fixed factors upon our three criteria: HYV adoption probability, farm profitability and output supply. All measures are presented in elasticity terms, evaluated at sample means (Table 4).

HYV adoption probability elasticities are computed from the probit estimate of (8). As discussed in section 3, $\mathrm{F}(\hat{\theta})$ represents the computed probability of HYV adoption. The derivative of the probability of adoption with respect to input price $P_{i}$ is given by $\frac{\partial F(\hat{\theta})}{\partial \ln P_{i}}=f(\hat{\theta}) \frac{\partial \hat{\theta}}{\partial P_{i}}$, where $f($.$) is the standard normal density function. Therefore, the$ elasticity of adoption probability with respect to input price $\mathrm{P}_{\mathrm{i}}$ can be expressed as:

$\frac{\partial \ln F(\hat{\theta})}{\partial \ln P_{i}}=\frac{\partial F(\hat{\theta})}{\partial \ln P_{i}} \frac{1}{F(\hat{\theta})}=\frac{f(\hat{\theta})}{F(\hat{\theta})} \frac{\partial \hat{\theta}}{\partial \ln P_{i}}$, which is easy to compute since the probit regressions (5) already has regressors appearing in logarithmic form.

The effects on farm profitability are measured by computing profit elasticities. In standard profit function models, profit elasticity expressions are easy to derive and calculate. For example, profit elasticity with respect to input price $P_{i}$ can be derived as follows.

By Hotelling's Lemma, $\frac{\partial \pi}{\partial P_{i}}=-X_{i}(P, Z)$. Profit elasticity is therefore given by $\frac{\partial \pi / \pi}{\partial P_{i} / P_{i}}=\frac{-P_{i} X_{i}(P, Z)}{\pi}=-S_{i}$, the $i$ th share equation. The estimated share equations can thus be readily used to calculate profit elasticities at sample mean values of exogenous variables.

However, under our variety-switching framework the measure are not straightforward. A change in a price or fixed factor causes a change in the probability that a particular variety is planted, and the profit elasticity measure has to account for such a shift. 
This can be seen by noting that the relevant profit measure, given a set of exogenous variables $(P, Z)$ is expected profit:

$$
E(\pi / P, Z)+\pi^{H Y V} \operatorname{Pr} o b(H Y V / P, Z)+\pi^{T V} \operatorname{Pr} o b(T V / P, Z)
$$

The elasticity measures have to be computed by taking the partial log-derivative of this expression with respect to the variable of interest. Evidently, this will include effects on the probability of adopting each variety. Output supply elasticities under a switching framework are also subject to similar considerations. The derivation of profit and supply elasticity expressions under the switching framework is relegated to the appendix.

The first column of Table 4 presents the HYV adoption probability elasticities. Output price seems to be a predominant factor influencing adoption of HYV rice as profitability would rise with increase in rice price. Since total input cost under HYV is higher than the TV, the relative profitability of HYV vis-à-vis TV production increases with better output price. All of the input price variables have expected negative signs. However, a reduction in labour wage would increase HYV adoption probability substantially, since HYV technology is demanding on all inputs including labour. This is because, HYV technology is a labour intensive technology and, transplanting in particular, requires large amount of labour in a short space of time where use of family labour only may not be sufficient. Previous studies \{e.g., Hossain (1989), Hossain et al., (1990) and Ahmed and Hossain, (1990)\} also confirmed that HYV rice technology uses significantly higher share of hired labour. The influence of fertilizers and animal power services are relatively small compared to labour wage, but are consistent with those obtained by Pitt and Sumodiningrat (1991) for Indonesia. One of the reasons for relatively lower influence of fertilizer price as compared to other two key inputs considered in this study may be due to the fact that farmers use a fixed dose of fertilizers at the outset (during the land preparation stage) when planting HYV rice in order to ensure a minimum level of yield to cover subsistence requirements. Also, Bangladeshi farmers use 
substantially lower level of fertilizers, about $40-70 \%$ below recommended levels (Ahmed, 2001), implying that a fall in fertilizer price will have the desired positive influence on HYV adoption probability but the magnitude is likely to be small .

The effect of land size is negative indicating that small farmers are more likely to plant HYV rice than larger farms. This finding may seem inconsistent against a priori assumption and warrants awareness of the actual condition that the farmers face in their pursuit of livelihoods. Rice is the staple crop in Bangladesh for all, which eventually forces small and marginal farmers to obtain as much output as possible from their limited amount of land (either owned or rented/leased in) to meet subsistence need at least. Therefore, planting HYV rice varieties instead of traditional varieties provides higher chances to meet this basic need, because the former is still capable of providing significantly higher yield. Availability of irrigation increases the probability of choosing HYV rice, consistent with the conventional expectation.

Level of infrastructure development is also an important factor indicating that HYV adoption probability decreases with infrastructure development ${ }^{6}$. This is because, in underdeveloped regions, adoption of HYV technology provides the best possible option to improve farmers' income as opportunities for producing high valued cash crops or seeking off-farm employment are highly limited. Therefore, given the limited amount of options to choose from, farmers in underdeveloped regions resort to produce HYV rice provided if opportunities for basic irrigation exists. Ahmed and Hossain (1990) found a positive but nonsignificant influence of infrastructural development on HYV adoption and concluded that "the effects of infrastructure are primarily indirect, through prices and technology adoption (i.e., irrigation). The direct effect (of infrastructure), which is independent of prices and technology is not significant" (pp. 36). We also find positive influence of irrigation on HYV 
adoption. Developed infrastructure, on the other hand, opens up various opportunities including scope for off-farm work and businesses, which presumably provides higher return than HYV rice farming, particularly for small and marginal farmers. Ahmed and Hossain (1990) concluded that infrastructure has profound impacts on the income of the poor in Bangladesh raising their income by $33 \%$, which includes doubling of wages and increase in income from business and industries by $17 \%$. The influence of farm capital assets and education is negligible although Pitt and Sumodiningrat (1991) noted positive effect of education on HYV adoption in Indonesia.

Seasonality has an important influence on HYV technology adoption as expected. The likelihood of adoption of HYV rice technology is significantly lower in Kharif season (the pre-monsoon and monsoon season). One of the main reasons is the cost of supplemental irrigation, which is estimated at $12.8 \%$ of gross value of output for HYV rice and only $2.6 \%$ for traditional rice (Rahman, 1998). Hence, farmers rely on monsoon rain for crop growth in the Aus and Aman seasons, and therefore, planting traditional variety is a preferred option. This perhaps explains why after four decades of thrust in the diffusion of the 'Green Revolution' technology, the composition of area allocated to traditional rice still revolves around 70\% in Aus and 57\% in Aman season, respectively (BBS, 2001).

Columns 3 through 7 of Table 4 present profit and output supply elasticities with respect to the price and fixed factors. Variety-specific elasticities as well as the overall or 'meta' elasticities that incorporate the variety-switching effects of the independent variable, are presented. The profit elasticities are all theoretically consistent (negative for input prices and positive for output price). A $1 \%$ increase in rice price increases overall farm profits by $1.8 \%$ as expected. Profits are relatively inelastic with respect to each of the three input prices. Farooq et al., (2001) also reported remarkably similar estimates of profit elasticities with

\footnotetext{
${ }^{6}$ The index reflects the underdevelopment of infrastructure, and therefore, a positive sign indicates a negative
} 
respect to prices of Basmati rice and the same three inputs in Pakistan Punjab. This provides useful insights for price policy in Bangladeshi agriculture. It shows that output price needs to be paid greater attention than to input prices. Although in the short-run, rising rice prices could increase vulnerability of the rural poor, in the longer run nearly half of such increase could be consistently passed on to the poor via increasing agricultural wages (Palmer-Jones and Parikh, 1998). Also, one of the principle arguments in favour of promoting HYV technology rests on the premise that part of the benefits accrued from producing HYV rice is transmitted to the marginal and landless farmers through the hired labour market as wages, since HYV technology uses significantly higher amount of hired labour than traditional technology (Hossain, 1989; Hossain et al., 1990). Our estimates of labour wage response to profits, though inelastic, indicates that a $1 \%$ rise in labour wages will reduce profitability by $0.4 \%$, thereby, lending support to aforementioned argument. Increase in land availability increases farm profits. A $1 \%$ increase in land supply would increase farm profits by $0.9 \%$. This is expected in a land scarce country like Bangladesh where per capita available land is only 0.06 ha (BBS, 2001). Infrastructure development also increases overall farm profits although a reduction in probability of HYV adoption was observed for developed regions.

The set of output supply elasticities also reveals the same story except one, the influence of infrastructure development. The implication is that output supply is higher in underdeveloped regions since adoption is higher although profits are not due to higher costs of inputs and perhaps transportation costs. Ahmed and Hossain (1990) noted significantly higher prices of fertilizer in underdeveloped regions. Apart from that, output price and land once again seem to be the key variables. A $1 \%$ increase in output price will increase output supply by $0.4 \%$. Similarly, $1 \%$ increase in availability of land would increase output supply

effect on the dependent variable (i.e., HYV adoption) and vice-versa. 
by $0.8 \%$. Farooq et al., (2001) reported similar response of output price and land availability in Basmati rice production in Pakistan Punjab.

Profit and output supply elasticities with respect to education are negative throughout although the effect is very small. This finding corroborates the hypothesis that increased education possibly leads to cultivators substituting their time inputs away from farming. Hossain (1989) noted negative effect of education on the probability of adoption as observed in our case. Rosenzweig (1981) postulates that education can affect adoption of new technology in different ways. On the one hand, it can encourage adoption by lowering learning costs. On the other, it may discourage adoption since education provides more profitable off-farm employment opportunities, and new technologies, if it is labour intensive, may reduce the ability of farm operators to substitute their time inputs away from cultivation.

\section{Conclusions and Policy Implications}

The adoption of HYVs, increased profitability of individual farming operations, and the accelerated supply of rice are important objectives for Bangladeshi agriculture. Most prior research has investigated these issues in a fragmented manner, often using ad-hoc models. In this paper, we have investigated the manner in which price and non-price factors affect these three criteria, based upon a model of rational variety choice. The model is empirically implemented using translog profit functions and a switching regression framework, and applied to a cross-sectional farm-level dataset of Bangladeshi farms in 1996.

The results provide some broad lessons for Bangladeshi agricultural policy:

(i) Maintaining high rice prices seem to be the most important factor as this would increase HYV adoption, overall farm profits as well as rice supply.

(ii) Although the conventional wisdom holds that input prices are key to the adoption of input-intensive HYVs, their effects are relatively small and secondary to output price effects except labour wages. 
(iii)Increase in availability of land is an important measure in a land-scarce country like Bangladesh.

Over the last 25 years, several reforms have taken place in the public foodgrain distribution system in Bangladesh. Government control has been focused on the maintenance of high prices in the harvest season, and foodgrain prices have, in general been allowed to rise close to the level of world prices (Ahmed, 1998). Given that the previous regime consisted of a public monopoly in distribution aimed at providing low prices for consumers, the reforms in the foodgrain sector seem to have provided the right incentives to rice producers. Agricultural input markets have also been rapidly liberalized in Bangladesh, and the fertilizer subsidy system was dismantled in 1992. Once again, this seems to be a wellconceived policy since the removal of subsidies has eased the budgetary burden, and according to our model, this policy does not have significant negative implications for HYV adoption, farm profitability and rice supply as the estimated impacts were rather small in all three cases. Development of infrastructure in rural regions also has a positive influence in increasing farm profitability through relatively lower costs and other facilities. Therefore, a combination of output price support policy as well as supplementary measures to improve land availability and rural infrastructure seems most desirable. We also provide evidence to support an extant hypothesis that more educated Bangladeshi farmers substitute their time inputs away from agriculture, resulting in lower HYV adoption, farm profitability and rice supply. 


\section{References}

Ahmad, Q.K., Hasanuzzaman, S.M. 1998. Agricultural growth and the environment. In Faruquee, R. (ed.) Bangladesh Agriculture in the $21^{\text {st }}$ Century. The University Press Ltd., Dhaka

Ahmed, R. 1998. Assessment of past agricultural policies. In Faruquee, R. (ed.) Bangladesh Agriculture in the $21^{\text {st }}$ Century. The University Press Ltd., Dhaka

Ahmed, R. 2001. Retrospects and Prospects of the Rice Economy of Bangladesh. University Press Limited, Dhaka.

Ahmed, R. and Hossain, M. 1990. Developmental impact of rural infrastructure in Bangladesh. IFPRI Research Report \#83. International Food Policy Research Institute, Washington, D.C.

Alauddin, M., Tisdell, C. 1991. The Green Revolution and Economic Development. MacMillan Press Ltd., London.

Antle, J.M. 1987. Econometric estimation of producer's risk attitudes. American Journal of Agricultural Economics, 69: 509-522.

Asfaw, A., Admassie, A. 2004. The role of education on the adoption of chemical fertilizer under different socioeconomic environments in Ethiopia. Agricultural Economics, 30: 215-228.

Azam, J-P. 1996. The impact of floods on the adoption rate of high yielding rice varieties in Bangladesh. Agricultural Economics, 13: 179-189.

BBS. 2001. Statistical Yearbook of Bangladesh, 1999. Bangladesh Bureau of Statistics, Dhaka.

Bera, A.K., Kelley, T.G. 1990. Adoption of high yielding rice varieties in Bangladesh. Journal of Development Economics, 35: 263-285. 
Besley, T., Case, A. 1993. Modeling technology adoption in developing countries. American Economic Review, 83: 396-402.

Brandon, C. 1998. Environmental degradation and agricultural growth. In Faruquee, R. (ed.) Bangladesh Agriculture in the $21^{\text {st }}$ Century. The University Press Ltd., Dhaka.

Davidson, R., MacKinnon, J.G. 1993. Estimation and Inference in Econometrics. Oxford University Press, New York.

Diewert, W.E. 1974. Applications of duality theory. In Intrilligator, M.D., Kendrick, D. (eds.) Frontiers of Quantitative Economics, Vol. 2. North Holland Publishing Co., Amsterdam.

Farooq, U., Young, T., Russell, N. and Iqbal, M. 2001. The supply response of Basmati rice growers in Punjab, Pakistan: price and non-price determinants. Journal of International Development, 13: 227-237.

Floyd, C., Harding, A-H., Paudel, K.C., Rasali, D.P. Subedi, K., Subedi, P.P. 2003. Household adoption and the associated impact of multiple agricultural technologies in the western hills of Nepal. Agricultural Systems, 76: 715-738.

Heckman, J. 1976. The common structure of statistical models of truncation, sample selection and limited dependent variables and a simple estimator for such models. Annals of Economic and Social Measurement, 5: 475-92.

Hossain, M. 1989. Green Revolution in Bangladesh: Impact on Growth and Distribution of Income. The University Press Ltd., Dhaka.

Hossain, M., Quasem, M.A., Akash, M.M., Jabber, M.A. 1990. Differential impact of modern rice technology: the Bangladesh case. Bangladesh Institute of Development Studies, Dhaka.

Kashem, M.A. 1987. Small farmer's constraints to the adoption of modern rice technology. Bangladesh Development Studies, 15: 119-130. 
Lee, L-F.1987. Unionism and wage rates: a simultaneous equations model with qualitative and limited dependent variables. International Economic Review, 19: 415-33.

Mahmud, W. 1998. Agricultural development strategy. In Faruquee, R. (ed.) Bangladesh Agriculture in the $21^{\text {st }}$ Century. The University Press Ltd., Dhaka.

Nkamleu, G.B., Adesina, A.A. 2000. Determinants of chemical input use in peri-urban lowland systems: bivariate probit analysis in Cameroon. Agricultural Systems, 63: $111-121$

Palmer-Jones, R., Parikh, A. 1998. The determination of agricultural wage rates in Bangladesh. Journal of Agricultural Economics, 34: 139-149.

Parikh, A., Bernard, A. 1988. Impact of risk on HYV adoption in Bangladesh. Agricultural Economics, 2: 167-178.

Pitt, M.M. 1983. Farm-level fertilizer demand in Java: a Meta-Production Function approach. American Journal of Agricultural Economics, 65: 502-08.

Pitt, M.M., and Sumodiningrat, G. 1991. Risk, schooling and the choice of seed technology in developing countries: a Meta-Profit Function approach. International Economic Review, 32: 457-473.

Rahman, 1998. Socio-economic and environmental impacts of technological change in Bangladesh agriculture. Unpublished $\mathrm{PhD}$ thesis. Asian Institute of Technology, Bangkok, Thailand.

Ransom, J.K., Paudyal, K., Adhikari, K. 2003. Adoption of improved maize varieties in the hills of Nepal. Agricultural Economics, 29: 299-305.

Rosenzweig, M.R. 1982. Agricultural development, education and innovation. In Greschwitz, M., Diaz-Alejandro, Ranis, G., Rosenzweig, M.R. (eds.) The Theory and Experience of Economic Development: Essays in honour of Sir W. Arthur Lewis. George Allen and Unwin, Boston. 
Shiyani, R.L., Joshi, P.K., Asokan, M., Bantilan, M.C.S. 2002. Adoption of improved chickpea varieties: KRIBHCO experience in tribal region of Gujarat, India. Agricultural Economics, 27: 33-39.

Sidhu, S.S., Baanante, C.A. 1981. Estimating farm-level input demand and wheat supply in the Indian Punjab using a translog profit function. American Journal of Agricultural Economics, 63: 237-246. 


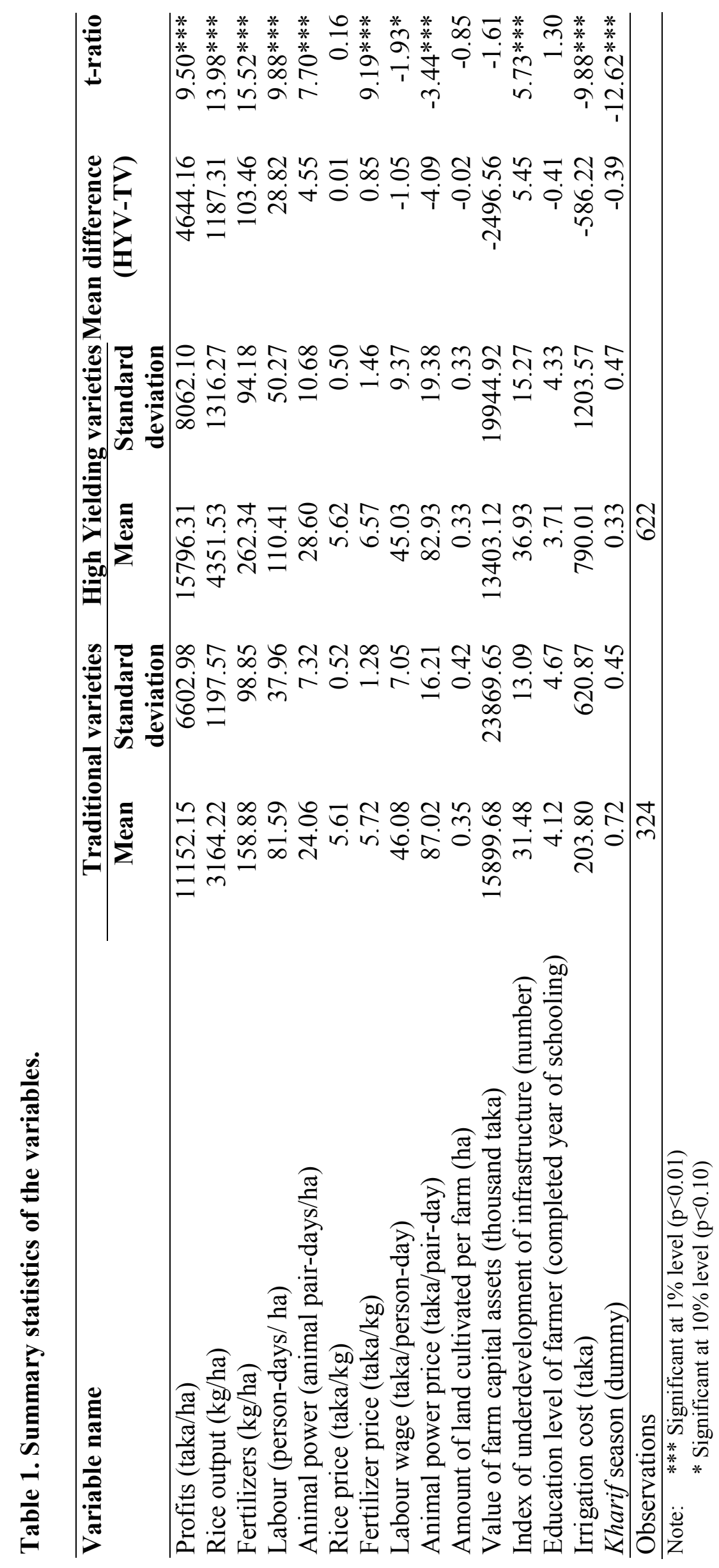




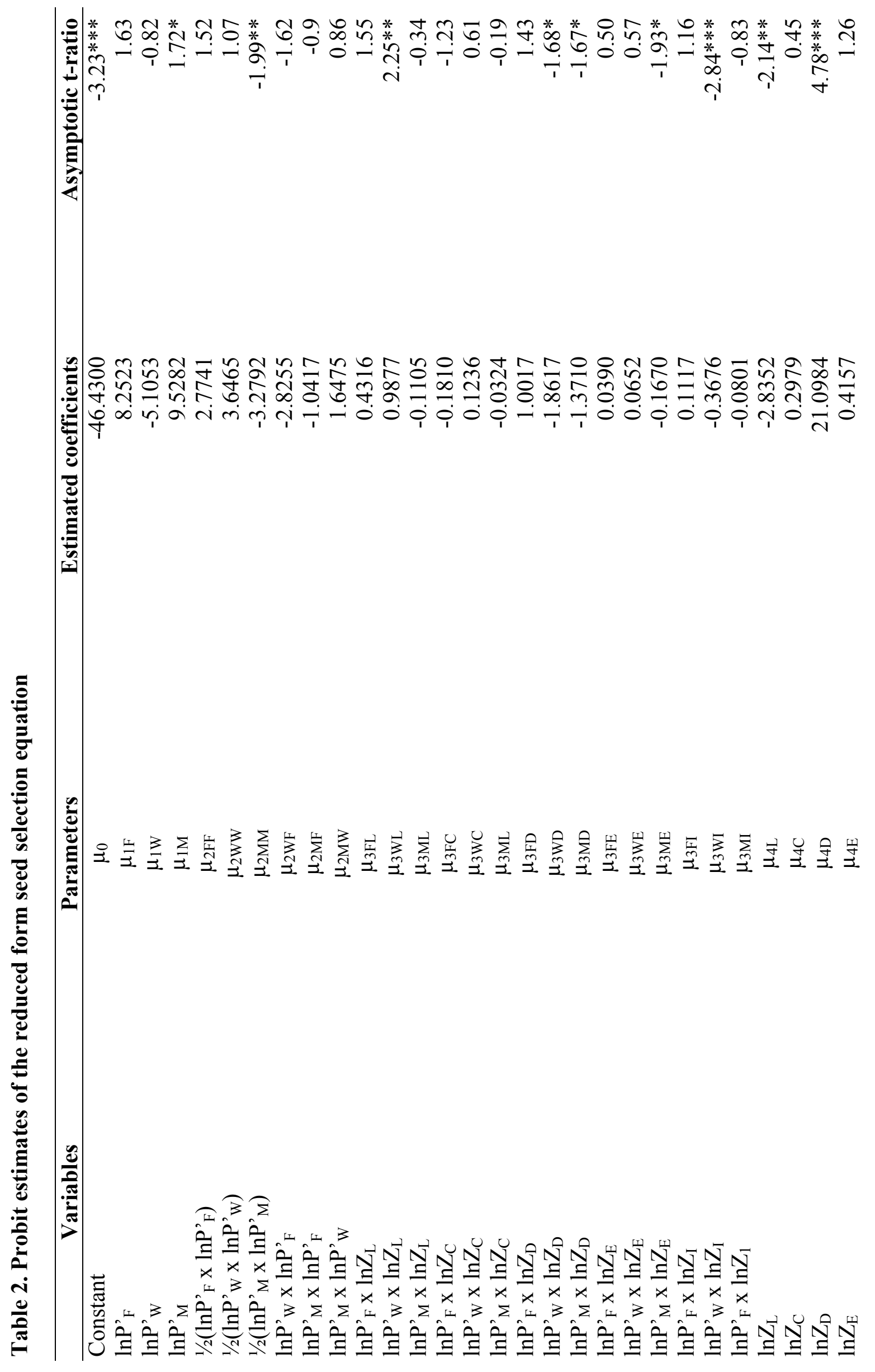




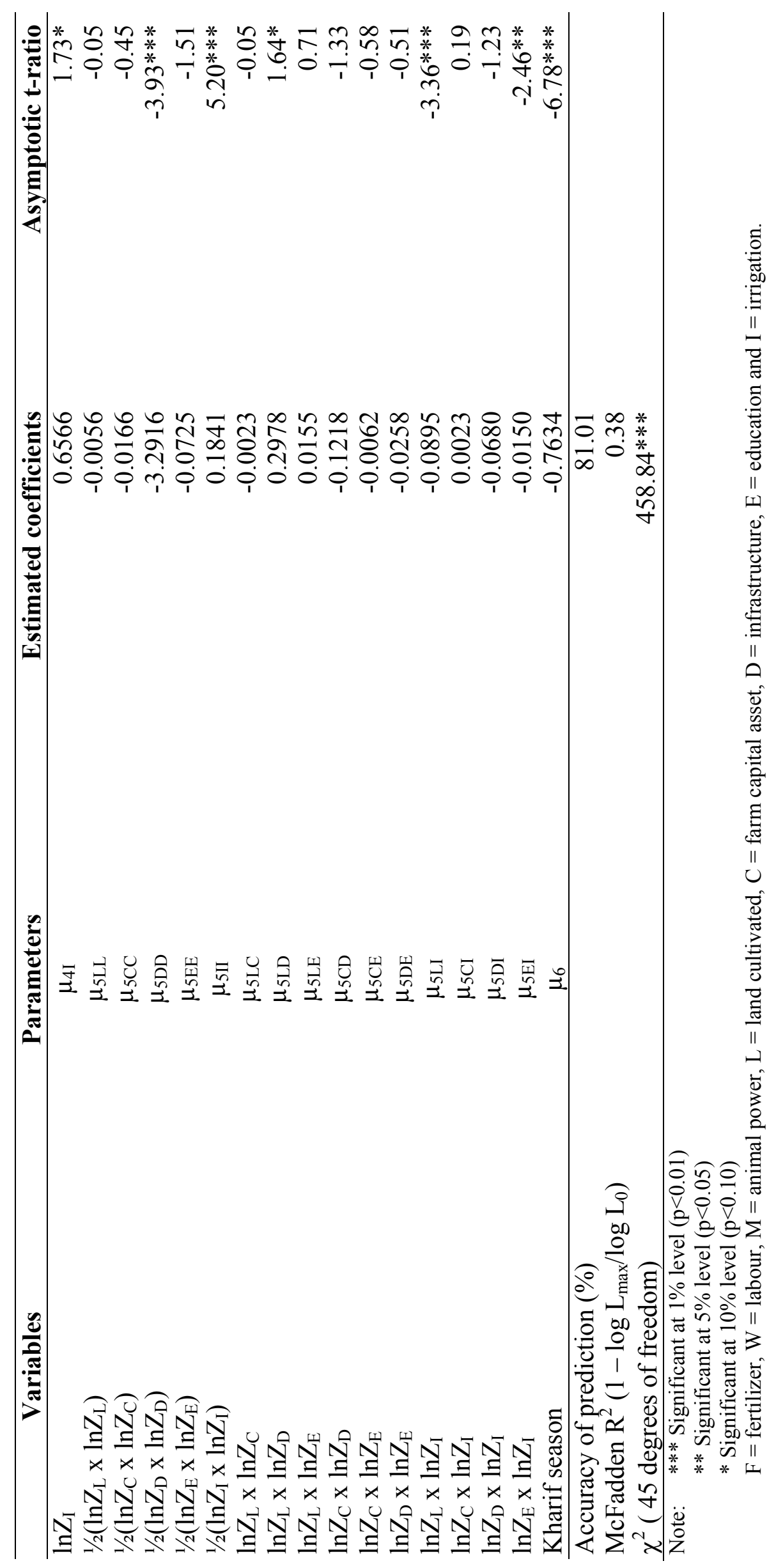




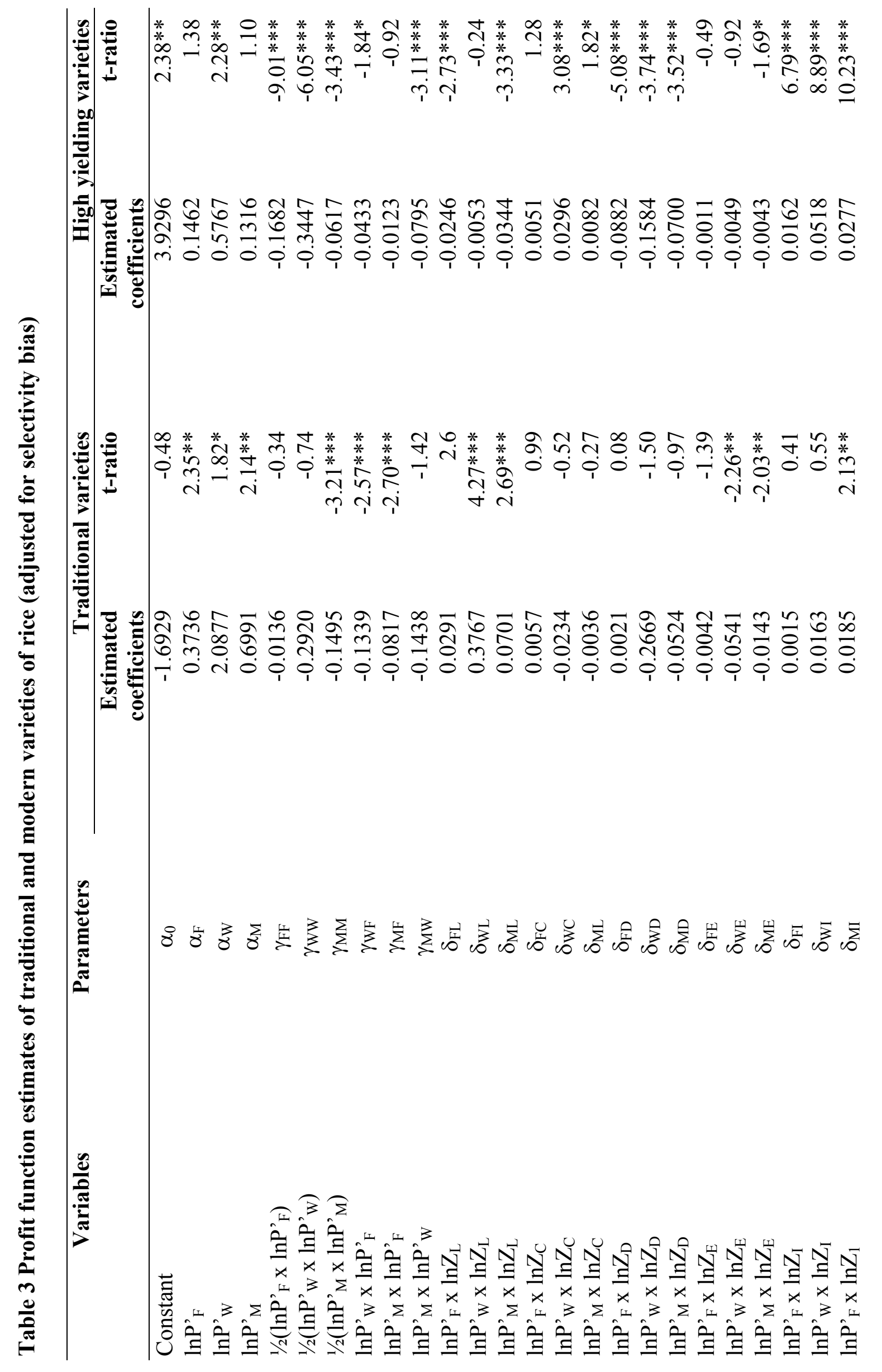




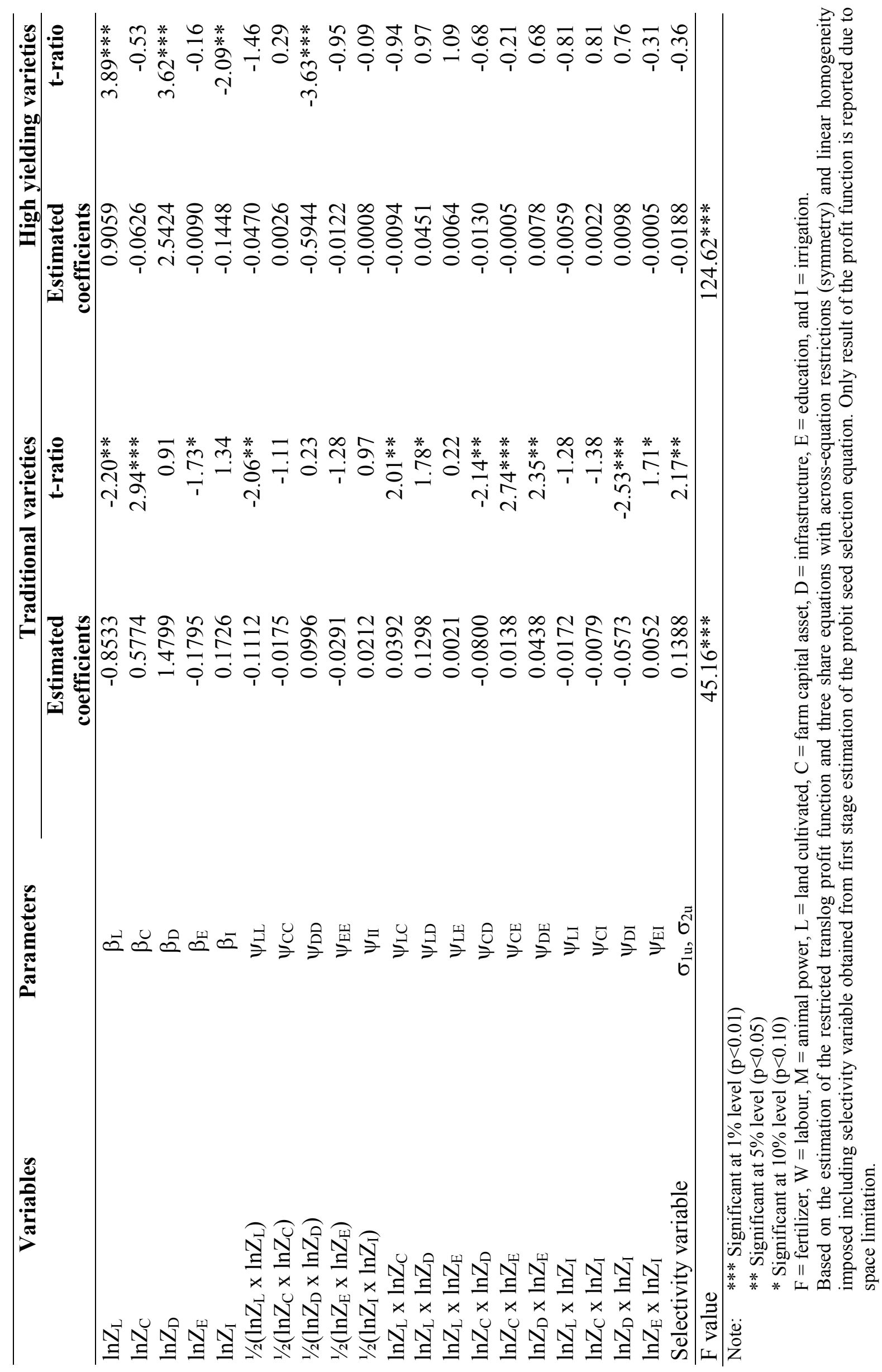




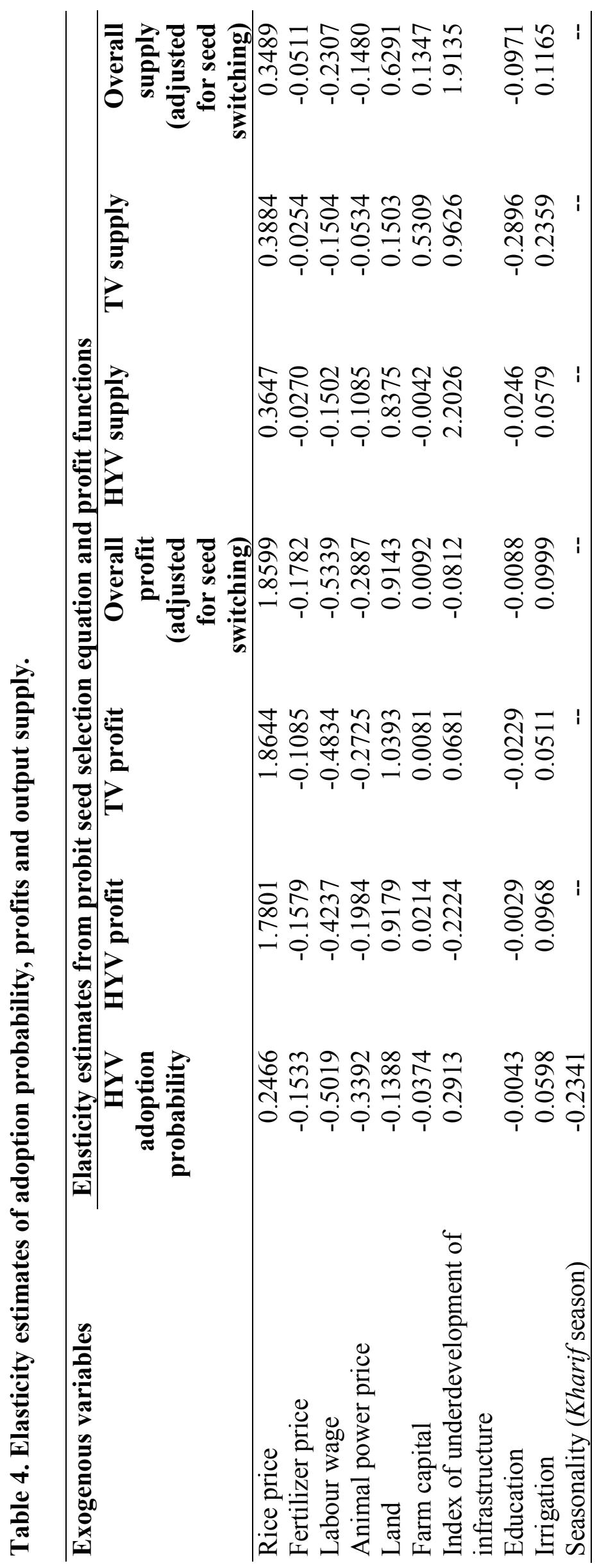




\section{Appendix: Profit and Supply elasticities under variety-switching}

Expected profit at $(P . Z)$ is given by:

$$
E(\pi / P, Z)=\pi^{H Y V} \operatorname{Pr} o b(H Y V / P, Z)+\pi^{T V} \operatorname{Pr} o b(T V / P, Z)
$$

We drop $(P, Z)$ from the notation for expositional convenience.

Profit elasticity with respect to input price $P_{i}$ is given by $\frac{\partial \ln E(\pi)}{\partial \ln P_{i}}=\frac{1}{E(\pi)} \frac{\partial E(\pi)}{\partial \ln P_{i}}$.

Differentiating (1a) with respect to $\ln P_{i}$ and dividing by $E(\pi)$, we can write:

$$
\frac{\partial \ln E(\pi)}{\partial \ln P_{i}}=\begin{aligned}
& \left\{\operatorname{Pr} o b(H Y V) \frac{\partial \ln \pi^{H Y V}}{\partial \ln P_{i}} \pi^{H Y V}+\operatorname{Pr} o b(T V) \frac{\partial \ln \pi^{T V}}{\partial \ln P_{i}} \pi^{T V}+\right. \\
& \left.\pi^{H Y} \frac{\partial \ln \pi^{H Y V}}{\partial \ln P_{i}} \operatorname{Pr} o b(H Y V)+\pi^{T V} \frac{\partial \ln \pi^{T V}}{\partial \ln P_{i}} \operatorname{Pr} o b(T V)\right\}
\end{aligned} / E(\pi)
$$

The term $\frac{\partial \ln \operatorname{Pr} o b(H Y V)}{\partial \ln P_{i}}$, the HYV adoption probability elasticity, has been computed before. Now, Prob(TV) $\equiv 1-\operatorname{Prob}\left(\right.$ HYV). Differentiating both sides with respect to $P_{i}$, we can write:

$\frac{\partial \operatorname{Pr} o b(T V)}{\partial \ln P_{i}}=-\frac{\partial \operatorname{Pr} o b(H Y V)}{\partial \ln P_{i}}$. Dividing both sides by Prob(TV) and simplifying enables us to write:

$$
\frac{\partial \ln \operatorname{Pr} o b(T V)}{\partial \ln P_{i}}=-\frac{\partial \ln \operatorname{Pr} o b(H Y V)}{\partial \ln P_{i}} \frac{\operatorname{Pr} o b(H Y V)}{\operatorname{Pr} o b(T V)}
$$

Rearranging and simplifying further, we can finally write the profit elasticity expression as follows:

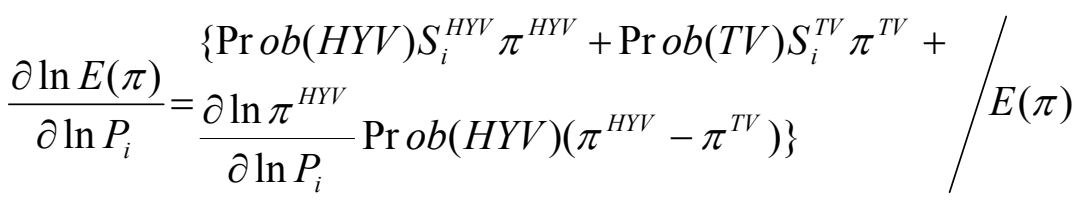

using similar logic, the following expressions can be derived: 
Profit elasticity with respect to fixed input $Z_{k}$ :

$\frac{\partial \ln E(\pi)}{\partial \ln Z_{k}}=\left\{\begin{array}{l}\left\{\operatorname{Pr} o b(H Y V) \frac{\partial \ln \pi^{H Y V}}{\partial \ln Z_{k}} \pi^{H Y V}+\operatorname{Pr} o b(T V) \frac{\partial \ln \pi^{T V}}{\partial \ln Z_{k}} \pi^{T V}+\right. \\ \left.\frac{\partial \ln \pi^{H Y V}}{\partial \ln Z_{k}} \operatorname{Pr} o b(H Y V)\left(\pi^{H Y V}-\pi^{T V}\right)\right\}\end{array} / E(\pi)\right.$

Profit elasticity with respect to output price $P_{y}$ :

$\frac{\partial \ln E(\pi)}{\partial \ln P_{y}}=\begin{aligned} & \left\{\operatorname{Pr} o b(H Y V)\left(\frac{\partial \ln \pi^{H Y V}}{\partial \ln P_{y}}+1\right) \pi^{H Y V}+\operatorname{Pr} o b(T V)\left(\frac{\partial \ln \pi^{T V}}{\partial \ln P_{y}}+1\right) \pi^{T V}+\right. \\ & \left.\frac{\partial \ln \pi^{H Y V}}{\partial \ln P_{y}} \operatorname{Pr} o b(H Y V)\left(\pi^{H Y V}-\pi^{T V}\right)\right\}\end{aligned} / E(\pi)$

Output supply elasticity with respect to input price $P_{i}$ :

$\frac{\partial \ln E(y)}{\partial \ln P_{i}}=\left\{\begin{array}{l}\left\{\operatorname{Pr} o b(H Y V) \frac{\partial \ln y^{H Y V}}{\partial \ln P_{i}} y^{H Y V}+\operatorname{Pr} o b(T V) \frac{\partial \ln y^{T V}}{\partial \ln P_{i}} y^{T V}+\right. \\ \left.\frac{\partial \ln \pi^{H Y V}}{\partial \ln P_{i}} \operatorname{Pr} o b(H Y V)\left(y^{H Y V}-y^{T V}\right)\right\}\end{array}\right.$

where $\frac{\partial \ln y}{\partial \ln P_{i}}=-S_{i}-\frac{\sum_{h=1}^{n} \gamma_{i h}}{1+\sum_{h=1}^{n} S_{h}}$

Output supply elasticity with respect to fixed input $Z_{k}$ :

$\frac{\partial \ln E(y)}{\partial \ln Z_{k}}=\begin{aligned} & \left\{\operatorname{Pr} o b(H Y V) \frac{\partial \ln y^{H Y V}}{\partial \ln Z_{k}} y^{H Y V}+\operatorname{Pr} o b(T V) \frac{\partial \ln y^{T V}}{\partial \ln Z_{k}} y^{T V}+\right. \\ & \left.\frac{\partial \ln \pi^{H Y V}}{\partial \ln Z_{k}} \operatorname{Pr} o b(H Y V)\left(y^{H Y V}-y^{T V}\right)\right\}\end{aligned} / E(y)$

where: $\frac{\partial \ln y}{\partial \ln Z_{k}}=\beta_{k}+\sum_{i=1}^{n} \delta_{i k} \ln P_{i}+\sum_{j=1}^{m} \psi_{k j} \ln Z_{j}-\frac{\sum_{i=1}^{n} \delta_{i k}}{\left(1+\sum_{h=1}^{n} S_{h}\right)}$ 
Output supply elasticity with respect to output price $P_{y}$ :

$\frac{\partial \ln E(y)}{\partial \ln P_{y}}=\begin{aligned} & \left\{\operatorname{Pr} o b(H Y V) \frac{\partial \ln y^{H Y V}}{\partial \ln P_{y}} y^{H Y V}+\operatorname{Pr} o b(T V) \frac{\partial \ln y^{T V}}{\partial \ln P_{y}} y^{T V}+\right. \\ & \left.\frac{\partial \ln \pi^{H Y V}}{\partial \ln P_{y}} \operatorname{Pr} o b(H Y V)\left(y^{H Y V}-y^{T V}\right)\right\}\end{aligned} / E(y)$

where $\left.\frac{\partial \ln y}{\partial \ln P_{y}}=1+\sum_{i=1}^{n} S_{i}\right)+\frac{\sum_{i=1}^{n} \sum_{h=1}^{n} \gamma_{i h}}{\left(1+\sum_{h=1}^{n} S_{h}\right)}$ 